Alma Mater Studiorum - Università di Bologna DEPARTMENT OF ECONOMICS

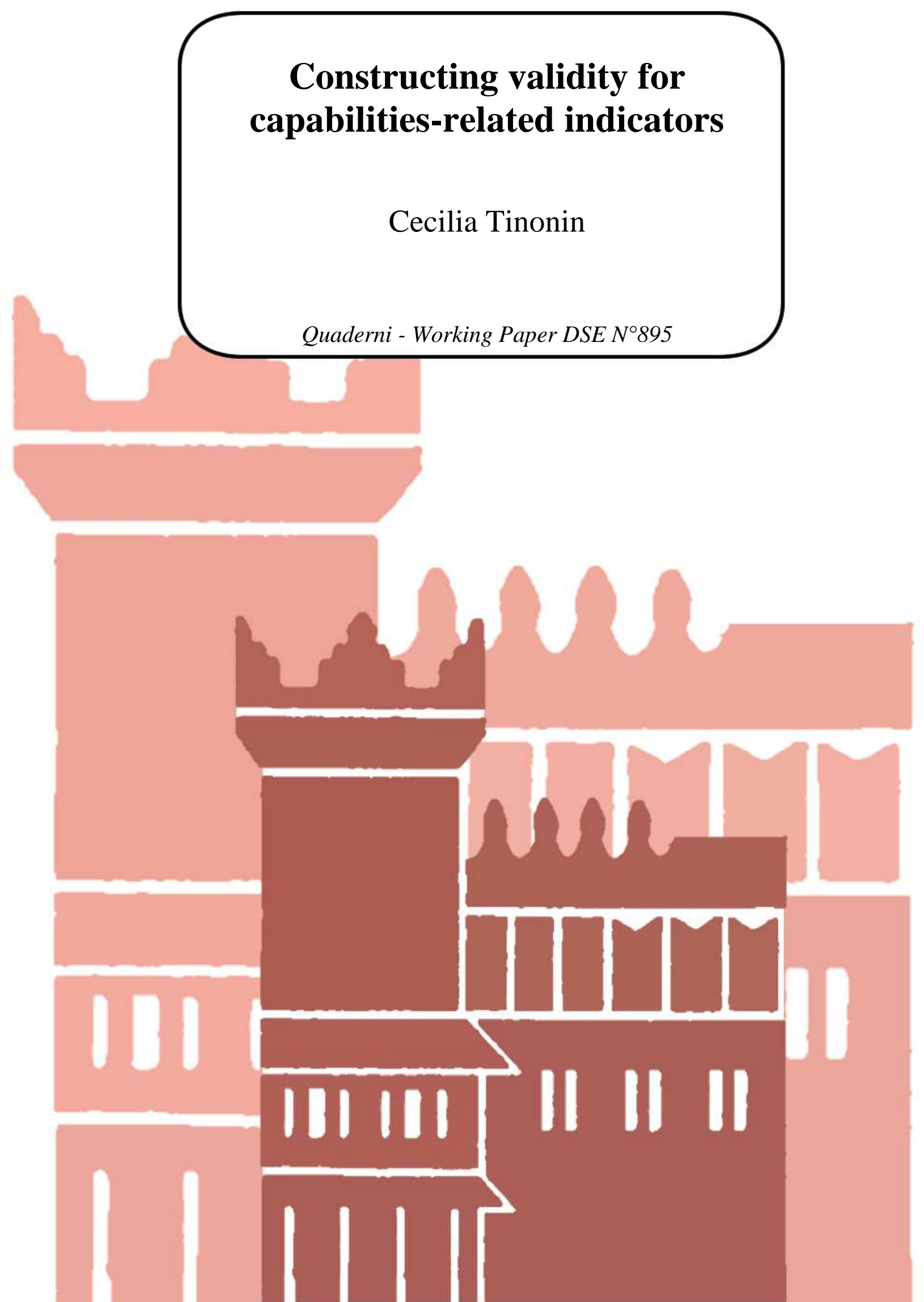




\title{
Constructing validity for capabilities-related indicators
}

\author{
Cecilia Tinonin \\ Dipartimento di Scienze economiche \\ Alma Mater Studiorum-Università di Bologna, Italy \\ cecilia.tinonin2@unibo.it
}

\begin{abstract}
Amartya Sen's approach to Welfare Economics argues evaluation of individual advantage should occur in the informational space of the freedom of choice individuals have in achieving valuable human functionings, that is in the space of capabilities. Furthermore, the identification of what is valuable involves taking into account ethical reasoning in the explanation of actual human behaviour, that is agency freedom, as well as the variety of human values. Despite of the recognition of such contribution to Economic Theory, unavailability of appropriate data and indicators challenges empirical investigations. This paper aims at overcoming such shortcoming through an assessment of the validity of an indicator measuring agency freedom as empowered autonomous choice. The empirical investigation is conducted on a random sample of 136 women in a rural patriarchal village in Uttar Pradesh, India, through a multi-topic survey instrument. Results indicate agency freedom differs across domains. In particular, individuals ranking high in the domain of resources simultaneously rank lower in the domain of empowerment. Furthermore, empirical evidence suggests a phenomenon of social exclusion of those more autonomous. Therefore, policy prescriptions at the community level identify enhancing collective capabilities as a viable strategy to accommodate the simultaneous coexistence of empowerment and social inclusion as well as the enhancement of principles of social justice rooted in a freedom-related metric.
\end{abstract}

Keywords: Agency, Capability Approach, Empowerment, Poverty, Time-Use. JEL codes: D69, I32.

I gratefully acknowledge financial support for this research from the Department of Statistical Sciences at the University of Bologna through the Marco Polo Fellowship. This study would have not been conducted without the supervision, direction, comments, and share of resources of the Oxford Poverty and Human Development Initiative (OPHI)'s team. In particular, I am extremely grateful to Sabina Alkire, José Manuel Roche and Sebastian Silva-Leander for their precious guidance during my academic visiting at OPHI. I am also grateful to Kimberly Fisher at the Centre for Time Use Research (CTUR) and to Vikas Rawal at the Centre for Economic Studies and Planning (CESP) at Jawaharlal Nehru University (JNU). Furthermore, Vaibhav Tripathi, Kirti Shukla, Priyanka Singh, Vikram Singh provided a crucial research support. Moreover, the paper greatly benefited from comments made by participants at the following seminars and conferences: Centro Studi sul Genere e l'Educazione (CSGE) Lunch Seminar, University of Bologna; Oxford Poverty and Human Development Initiative (OPHI) Lunch Series Seminar, University of Oxford; Human Development and Capabilities Association (HDCA) Conference, The Hague; the International Statistical Institute's (ISI) Conference, Dublin; the Social Economy and Civil Society Workshop of Young Economists, University of Bologna. All errors remain mine own. 


\section{Introduction}

Empowerment increasingly plays a central role in poverty reduction strategies because of its intrinsic as well as instrumental relevance in breaking down vicious circles of misery and deprivation (Narayan, 2005; Samman and Santos, 2009). The specific term refers to an act of choice related to "agency, autonomy, self-direction, self-determination, liberation, participation, mobilization and self-confidence" (Ibrahim and Alkire, 2007, p. 383). In other words, the overall concept deals with the decision-making process leading disadvantaged individuals to opt for those alternatives enabling them to escape poverty and to sustain well-being in the long-run (Narayan, 2002, 2005). ${ }^{1}$ According to the traditional postulate of rationality, the utilitarian perspective assumes empowerment to be merely directed at improving the agent own life's circumstances conditional to one's expectations. Furthermore, it proposes monetary indicators, such as control over resources as a share of expenditures, to empirically measure the concept. Also, it calls for enlarging the budget constrain of recipients of public interventions for incentivizing empowered behavior. Hence, a symbiotic identification is at stake here. That is, an increased ability of consuming goods and services in the market economy necessarily translates into higher autonomy and vice versa. Indeed, the 'economic dimension' of empowerment is the most frequently studied (Narayan, 2005, p. 20 and references therein).

Amartya Sen's approach challenges such traditional view through an alternative framework shaping empowerment in terms of agency freedom. In explaining actual human behavior, the normbased approach argues in favor of accounting for the ethical views of individuals when tackling motivations behind choice (Sen, 1994). Thus, the inclusion of the philosophical notion of human agency into economic theory recognizes the moral value of other-regarding aspects for human nature, such as those connected with altruism, social norms, ethics and codes of conduct. In line with Aristotle's heritage, such perspective envisions empowerment in terms of the freedom individuals have in choosing among alternative views of 'what a good life is'. Consequently, agency freedom should not be a priori and normatively endowed with instrumental value in increasing one's own utility and wellbeing. And, it should not be necessarily translated through a monetary-metric (Sen, 1985). Yet, despite the tremendous advancements in measuring well-being as a composite indicator in the multidimensional space of outcomes (Alkire and Foster, 2011), the non-utilitarian perspective still lacks a sound theoretical formalization of its underpinnings as well as freedom-oriented indicators for empirical investigations. ${ }^{2}$

Following the Oxford Poverty and Human Development Initiative's (OPHI) literature on the operationalization of Sen's approach, this paper aims at developing and validating an indicator rooted in a freedom-related metric. In particular, it evaluates strengths and weaknesses of the OPHI's survey module for Agency and Empowerment, focusing on the psychological dimension of agency freedom, 'which is the least studied of all' (Narayan, 2005). ${ }^{3}$ Thus, the present contribution assesses the validity of questions not previously and widely tested, such as those related to the measurement of empowerment as the power to change and empowerment as autonomous choice. Furthermore, it investigates main characteristics of empowered and dis-empowered and tests whether achievements over multiple domains overlap.

The paper is structured as follows. Section 1 lays down the conceptual framework for agency freedom and its empirical measurement. Section 2 outlines the methodology employed for primary data collection. Section 3 presents main characteristics of the sample, whereas Section 4 assesses the quality of data collected through tests of reliability. Section 5 constructs the Relative Autonomy Index to investigate systematic differences between empowered and dis-empowered. Section 6 concludes.

\footnotetext{
${ }^{1}$ Ibrahim and Alkire (2007) provide a list of 29 of the many definitions of empowerment currently in use.

2 (Silva-Leander, 2011a, 2011b)

${ }^{3}$ In particular, the starting point of the present contribution is to be found in relation to the OPHI's Seminar, "Towards an Autonomy Scale for Poverty Analysis: Validity and Reliability Evaluation with psychometric techniques for scale construction", held on $16^{\text {th }}$ November 2010, by Josè Manuel Roche and Jessica Morgan.
} 


\section{The conceptual framework for empirical investigation}

Sen's approach to Welfare Economics argues evaluation of states of affairs should occur on an informational space composed of enriched utility information as well as of non-utility information, such as those related to functionings and capabilities (i.e. liberties and rights). In particular, the metric of the focal variable relates to the freedom individuals have in pursuing 'the life they value and have reason to value'. Thus, information on the existence of an alternative (i.e. necessary condition for the existence of a choice function) as well as on the decision-making procedure are the two founding aspects of freedom of choice, that are respectively the opportunity and the process aspect. Furthermore, arguments in support of such informational broadening are simultaneously pursued alongside arguments for weakening the consistency conditions behind a choice function (Sen, 1982, 2002; Silva-Leander, 2011). Thus, external correspondences between outcomes of choice on the one hand and aims, objectives and values on the other hand allow to account for the ethical view of individuals on what makes an existence valuable (Sen, 1994, 2002). ${ }^{4}$ The introduction of human agency into economic theory, therefore, conceptualizes agents as also capable of commitment (e.g. choosing an act that he/she believes will yield a lower level of personal welfare to him/her than an alternative that it is also available to him/her) in contrast with a view according to which every agent is actuated only by self-interest (Sen, 1977).

To empirically measure such theoretical apparatus so as to address previously neglected aspects of agency (i.e. autonomy, effective power and other-regarding goals), Alkire (2005) proposes a line of inquiry, further developed in Ibrahim and Alkire (2007), Alkire (2008) and Alkire and ChiapperoMartinetti (2008), which builds on Self-Determination Theory (SDT). Proposed in the field of existential positive psychology (Ryan and Deci, 2000), SDT is 'an empirical approach to motivation, development, and personality that is deeply concerned with the dynamics of autonomy, with regulation by the self. [...] SDT has examined the conditions that make it more or less possible to be autonomous or volitional and has shown how differences in the degree of autonomy affect human functionings and experience. That is, our interest is in the interplay between the vulnerabilities for being controlled and the possibilities for vital, authentic living' (Ryan, Deci, 2004; p. 455). ${ }^{5}$ Hence, both the CA and the SDT identify freedom and autonomy as the crucial aspect for enhancing individual well-being. Also, they both view heteronomy (e.g. a lack of process freedom) to be accounted as among determinants of illbeing and dysfunctional human living.

As such, autonomy results in intrinsically motivated actions, which in turn refers to willingly enacted behavior and those activities pursued coherently with 'authentic interests or integrated values and desires' (Alkire: 2005, p. 242). On the opposite side are instead those behaviors pursued without any intention to act, that is just going with the motion. ${ }^{6}$ In between such two extremes, SDT categorizes extrinsic behavioral regulations alongside four types of motivations standing on an underlying continuum of autonomy. In describing their contents, Ryan and Deci (2000) point out the least autonomous is behavior externally regulated, such as behavior 'performed to satisfy an external demand or reward contingency. Individuals typically experience externally regulated behavior as controlled or alienated, and their actions have an external perceived locus of causality'. Furthermore, introjected regulation 'involves taking in a regulation but not fully accepting it as one's own. It is a relatively controlled form of regulation in which behaviors are performed to avoid guilt or anxiety or to attain ego enhancements such as pride'. Moreover, identified regulation 'reflects a conscious valuing of a

\footnotetext{
${ }^{4}$ For instance, accounting for ethical motivation behind behavior could make the choice of a given vector of functionings within a matrix of potential functionings (capability set) not necessarily the optimal. Nevertheless, the rationality of such choice can be argued if some information is provided on what the individual is attempting at achieving (see Sen: 1994).

${ }^{5}$ For further references, please see: Deci, E.L., Ryan, R.M., (1985) Intrinsic Motivation and Self Determination in Human Behavior. Perspectives in Social Psychology, Plenum Press; Deci, E.L., Ryan, R.M., (2002) Handbook of Self-Determination Research, University of Rochester Press; Chirkov, V.I., Ryan, R.I., Sheldon K.M., (2011) Human autonomy in cross-cultural context: perspectives on the psychology of agency, freedom, and well-being, Springer.

${ }^{6}$ For instance, SDT shows that people whose motivation is authentic, that is self-authored and endorsed, have more interest, curiosity, confidence, which in turn enhance performance, persistence, creativity, self-esteem, and general wellbeing, then those people whose motivation is externally controlled.
} 
behavioral goal or regulation, such that the action is accepted or owned as personally important'. The last category of extrinsic motivation is integrated regulation, which is 'closely related to intrinsic motivation but still different as it concerns actions aimed at achieving separable outcomes rather than for their inherent enjoyment' (Ryan and Deci, 2000).

Taken together extrinsic motivation's categories describe the process of internalization of heteronomy (i.e. regulation from outside the self by forces experienced as alien or pressuring such as inner impulses or demands, or external contingencies of rewards and punishment). In simpler words, it refers to people's 'taking in' a value or a behavioral regulation. The engine behind such process is to be found in relation to the basic human need of relating to others and properly function within the social environment. Once values have been internalized, integration with the self takes place. That is, the regulation is transformed into one's own so that, subsequently it will emanate from the sense of the self' (Ryan and Deci: 2000, p. 71). Overall, extrinsic motivations refer therefore to different degrees of relatively autonomy. That is, 'different degrees to which the value and regulation of the requested behavior have been internalized and integrated' (Ryan and Deci, 2000).

\section{Methodology for primary data collection}

To operationalize such conceptual apparatus, a primary data collection was conducted on a random sample in the village of Sankraud, in the district of Baghpat, India, in April 2010 after three months of expert-interviews, field visits, logistic set-up, enumerators training and questionnaire pretesting. The main purpose of the investigation was twofold. First was the aim to collect an informational basis adequate to build a direct domain-specific indicator of relative autonomy. The second objective was to allow the empirical investigation to address the association between such indicator and the nutritional status of children in the age group 0 to 3 years old. Therefore, the selection of the geographical area was based on a mapping study carried out by the Ministry of Women and Child Development Service in cooperation with the World Bank (WB) in 2008. ${ }^{7}$ Using data from the District Level Household Survey-II (2002/04), the WB's study ranks the district of Baghpat as worst on the basis of a composite indicator accounting for low nutritional status of children below six years and anemia among pregnant women belonging to the age group 14-44 years.

Situated in the Northern State of Uttar Pradesh, the district of Baghpat - known in Hindi as 'the Land of Tigers'- is defined by a vibrant primary sector particularly flourishing due to its proximity to the two main Indian rivers, namely Yamuna and Ganges. Among 315 villages in the district, the survey design purposely selected the village of Sankraud as the high crime prone area required increased safety and logistic measures. ${ }^{8}$ Furthermore, the sampling methodology foresaw drafting an ex-novo sampling frame to list all households in the village where a child aged 0-3 years was member. Indeed, preliminary field visits pointed out potential source of sampling bias in existing sampling frames due to underreporting of sampling units. Also, the methodology exploited the internal division of the village into mohallas (local administrative units). From each mohalla, a simple random sample was drawn maintaining a constant proportion between sampling and sampled units. Under budgetary and time constraints, the total sample size was 128 households out of 273 households listed in the target population.

The methodology for data collection -face-to-face (self-reporting) at home interviews- had to take into serious account the patriarchal structure shaping gender relations both at the household and the community level. ${ }^{9,10}$ For this reason, at the field level the overall survey team divided in two groups.

\footnotetext{
7 Tool Book ICDS-IV Project (2008-09 to 2012-2013) Central Project Management Unit, Ministry of Women and Child Development Service, Government of India.

8 According to the latest figures available at the village level provided in the Indian Census, the total population of the village in 2001 was 5,937 inhabitants, where total male population was 3,197 and total female population was 2,740.

${ }^{9}$ For instance, the practice of wearing a purdah is still nowadays widespread.

${ }^{10}$ As Sen noted (2001; p.12), the vast majority of Indian States can be categorized into two contiguous halves, classified broadly into the North and the West, on the one side, and the South and the East, on the other. The modality for such dichotomous distinction relates specifically to gender inequality. Thus, every state in the North and in the West is
} 
Each group consisted of a female and a male enumerator. Every team interviewed one household at a time so that in an hour two households were simultaneously interviewed. Questionnaires were field checked by the researcher, who was present during the entire process of data collection. ${ }^{11}$ Particular care was devoted to the methodology for agency-related data because of information sensitivity. Thus, the survey design established the informant had to be alone when answering to questions on autonomy and relations of power within the household. Hence, external pressure on the respondent was minimized through the implementation of two different survey instruments, namely the Household Questionnaire (HQ) and the Child and Mother Questionnaire (CMQ). The mother-in-law and other members of the household were identified as respondents of $\mathrm{HQ}$, whereas the female enumerator interviewed the mother of the child through the CMQ in a separate location within the same dwelling unit.

The survey design foresaw the HQ to collect resources-based information at the household level and the CMQ to focus on individual level data. To such aim, the survey instrument draw modules from the WB's Living Standards Measurement Survey conducted in Bihar and Uttar Pradesh in 1998/1999, whereas the CMQ draw survey questions on health-related information as laid out in the National Health and Family Survey (NHFS) conducted in India in 2005/06. Primary data collection, also, included the OPHI's Module on Agency and Empowerment, which applies the SDT's scale to specific domains (i.e. employment, household duties, responses to an health crises, mobility). Furthermore, it adds a fifth modality, namely no control to account for the 'respondent's possible inability to make choices in a particular domain not due to external coercion but rather due to force of circumstances' (OPHI Technical note). ${ }^{12}$ Semantic response items vary in degrees of truthfulness (i.e. not at all true, not very true, somewhat true, completely true) 'since certain choices and practices are not mutually exclusive and can coexist to different degree'. Moreover, survey instruments related to empowerment as change address whether the respondent has the ability to change some areas in her life, what areas would like to change and who has the power to change. Lastly, the CMQ included a 24hours recall Time-Use diary, which was designed taking as reference the Indian Time-Use Survey (ITUS) conducted in 1998/99.

\section{Characteristics of a patriarchal sample}

The survey collected information on a random sample of 128 households. Among them, 51 were Muslim (40\%) and 76 Hindu (60\%). ${ }^{13}$ The survey design did not categorize caste prior to fieldwork. After data collection, the open question reported 21 sub-castes present in the village. Being the sample size relatively small for conducting an analysis at such level, a new variable is coined to translate the 21 sub-castes into the three general categories as identified by the Indian Government. Accordingly, 96 households declared to belong to a Other Backward Caste (75\%) (OBC), 20 households (16\%) to belong to Scheduled Caste (SC) and $12(9 \%)$ to the higher General Caste (GC). At the individual level, the sample covers 136 women whose age ranges from 17 to 36 years. ${ }^{14,15,16}$

\footnotetext{
distinguished by a strictly lower female-ratio of children than has every State in the East and the South. The gender inequality divide stems from, and in turn is reinforced through, the patriarchal kinship system characterizing social structure of this area.

11 If inconsistency were found, the team went back to the selected household and clarified doubts. Data entry was also performed by enumerators after the survey ended so that if there were additional inconsistencies, it would had been possible to visit the village to clear them out. However, systematic data cleaning was carried out and discrepancies were solved only with reference to the questionnaire.

${ }^{12}$ Differences between the OPHI's Module on Agency and Empowerment and SDT's survey questionnaire are to be found. In particular, the SDT's survey instrument includes amotivation (i.e. lack of intention to act) and intrinsic motivation (i.e. activities related to the inner satisfaction). Furthermore, the latter implements a Likert-scale on 7 or higher points.

${ }^{13}$ The coexistence of the two religious groups into the same village is in line with the population's features at the district level. For reference, please see Statistical Booklet, Baghpat Janpad, Economics and Counting office, State Planning Institution, Economic and Counting Division, Uttar Pradesh (2008).

${ }^{14}$ The difference between the number of respondents for the HQ and the CMQ is explained by the presence of eight joint families, which by definition eat and share resources under the same dwelling unit.
} 
Furthermore, a new indicator of age, labeled aget, is constructed on the basis of the age-at-marriage plus the number of years the woman has been living in the community conditional to whether she moved to the community at the time of marriage. Such reasoning appear to be meaningful considering 132 women moved to the village when they got married, whereas only 3 did already live there. Computation of aget yields a new variable ranging from 17 to 40 years with a mean value equal to 25.75. On average, the difference between age reported and age calculated on the basis of further information is -0.42 years.

As primary occupation, all women declared to be housewives. Only 23 women were also engaged in a secondary occupation. ${ }^{17}$ In terms of education, $35 \%$ of respondents were non-literate, $3 \%$ knew how to read and write without having attended formal schooling, whereas the remaining $62 \%$ achieved a level of education equal or above primary education. ${ }^{18}$ The survey design included an anthropometric module in order to provide objective indicators of deprivation. As result, weight was recorded for 104 cases. The mean value is 50.6 kilograms (s.d.=8.31) ranging from 34.2 to 76.2 kilograms. Height was recorded for 98 cases and its mean value is 153.6 centimeters varying from 139 to 172 centimeters. Accordingly, the Body Mass Index (BMI) is constructed only for those cases for which both weight and height are available. The distribution of the BMI ranges from 14.1 to 30.4 and it averages at 21.2 (s.d.=3.24). Hence, the sample reports both cases of underweight $(n=19)$ as well as overweight $(\mathrm{n}=12)$. Among the cases for which the BMI is inadequately low, $90 \%$ of observations belong to lower casts, namely OBC (79\%) and SC (11\%).

Anthropometry is also crucial in comparison with subjective indicators of life-satisfaction. Despite objective manifestation of deprivation occurs in the sample, figures on hedonistic well-being overall yield an high degree of life satisfaction. ${ }^{19}$ All things considered, $57 \%$ of respondents declared to be very satisfied with their own life, $32 \%$ to be satisfied, $7 \%$ neither satisfied nor dissatisfied and only $4 \%$ reported dissatisfaction with their life. Interestingly, none replied to be very dissatisfied. Zooming in on the perception of satisfaction with one's own life, the Module on Empowerment as Change appears to be particularly meaningful in underlining the need to complement subjective indicators of life with supplementary information. Despite declaring to be very satisfied or just satisfied, 77 women also declared they want to change something in their own life, whereas among 9 women declaring to be neither satisfied nor dissatisfied, 8 women reported to be interested in changing something. Only 44 women demonstrated some consistency between the two questions reporting simultaneously a high degree of life satisfaction and the absence of an interest in changing something in their own life. Furthermore, an open question investigated what women actually wanted to change. Answers were codified after data collection to avoid conditioning informants towards particular domains. As result, five domains were identified. First is education, which covers 'education for 'education for children' and 'education for myself. Second is bealth, which covers improvement of health care facilities and health

\footnotetext{
15 Out of 134 respondents, only 115 women declared their age, which mean values is 25.05 years (sd=3.62). As previously assumed, more respondent were capable of providing information on their age at marriage $(\mathrm{n}=124)$ rather than their actual present age $(n=115)$. Furthermore, the mean value for age at marriage is equal to 18.55 years (sd=0.23) pointing out the persistence of early childhood marriage. Indeed, the distribution of individuals according to age at marriage reports $33.06 \%$ of cases getting married before the legal age.

${ }^{16}$ Primary data collection was particularly successful in minimizing missing cases. For the HQ, one missing case is recorded due to refusal to participate to the survey. The same missing case applies to the CMQ, which also includes another missing case due to the impossibility of finding the mother at home even after several attempts.

17 The survey design drawn from the Living Standard Measurement Survey, conducted by the World Bank in Bihar and Uttar Pradesh in 1998/99, the categorization of employment status, which was collected at the individual level within every single household. Among the 23 women declaring to be involved in a secondary activity, 12 women declared to be occupied in their own farm activity, 10 to be casual labor and 1 to be retired and too old to participate to the labor market. Also, among them, 14 were non-literate, 1 did know how to read and write without formal schooling, whereas only 7 achieved a level of education equal or above primary but below the intermediate level.

18 The median for the sample is middle school.

${ }^{19}$ Such result is in line with the argument of adaption CA's theorists adopt in favor of more objective metrics for the evaluation of well-being. See for instance: Clark, D. A., (2009) Adaptation, Poverty and Well-Being: Some Issues and Observations with Special Reference to the Capability Approach and Development Studies, Journal of Human Development and Capabilities, Vol. 10, No. 1, pp. 21-42, and references therein.
} 
for women and their husbands. Third is employment, which covers not only a job to earn money but also specific functionings, such as learning how to stitch. In this category falls also the desire for more 'money'. Forth is living standards, which includes better housing, housing outside the village, improved food provision, and higher living standards as an overall concept. The fifth domain relates to higher functionings, such as the religious functioning of visiting Medina and being bappy. The same domains are also identified when women were asked what they would require if the Government implemented a policy aimed at improving their well-being.

If on the one hand informants clearly identified the specific domains for change, on the other hand they reported a lack of decision-making power in acting towards achieving such transformations. When asked who they think would contribute the most to those changes they wish to undertake in their life, almost $77 \%$ of women identified their husbands, $17 \%$ their families and only 2 women reported they could have a say for those changes they would like to happen in their lives. ${ }^{20}$ Direct questions on decision-making power confirm such feature. In particular, Table 1 shows a very low decision-making power of women with regards to being employed, seeing a doctor, moving around the community and spending money. On the other hand, the only life sphere in which the majority of women declared to have great control is the realm of household duties (81\%).

Table 1: Who in your household does decide on the following? (percentage)

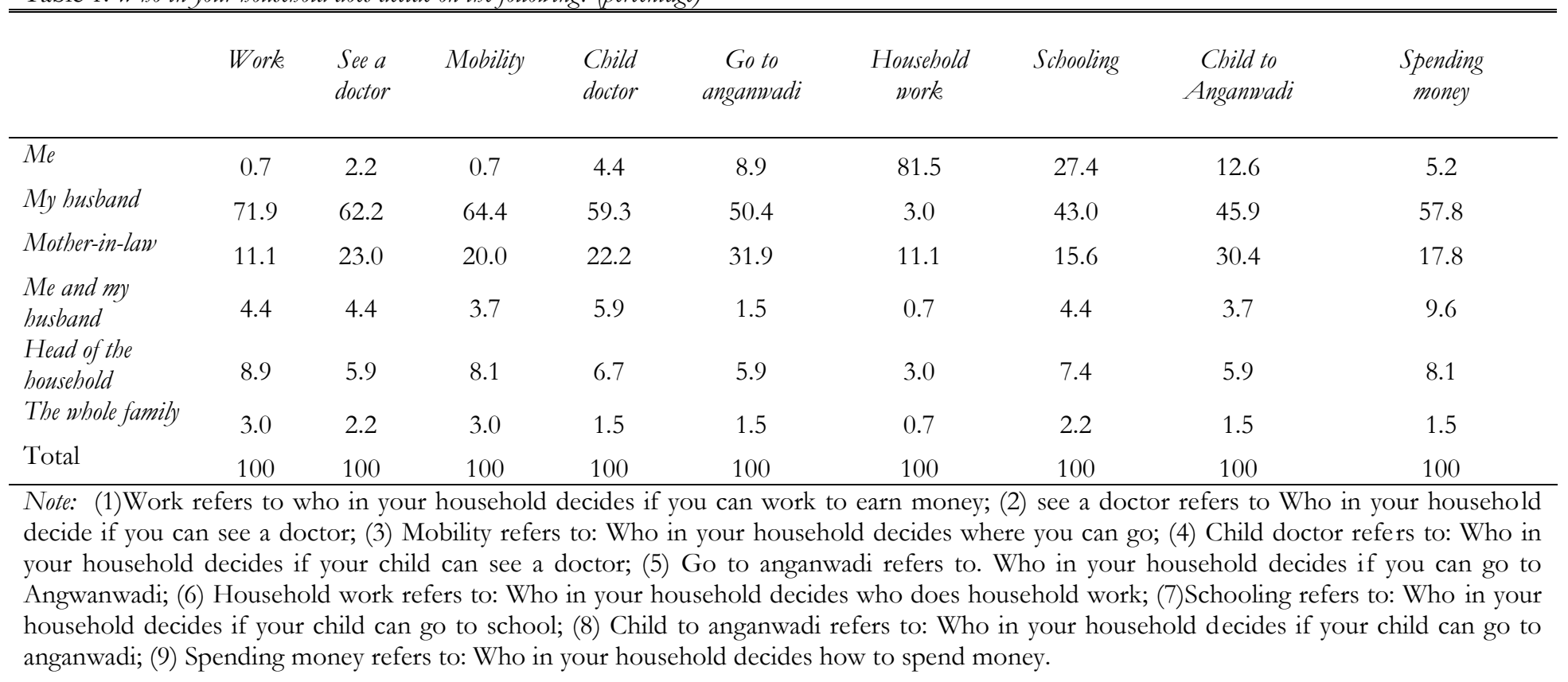

\footnotetext{
${ }^{20}$ Respondents identified as main decision maker not only the husband, as it could be expected in the area, but also the mother-in-law. Qualitative interviews pointed out the husband as main decision making power also because, in the case conflict arise within the household, the dispute would be solved between the husband and the mother-in-law. Such aspect may have relevant implications in terms of public policies for empowerment.
} 


\section{Reliability of the agency's scale in basic domains}

When the same underlying concept is measured through multiple qualitative items, the first step for assessing the quality of the data collected is to check the reliability of the scale employed. In particular, when the objective is to verify whether different items measure the same underlying concept at one point in time, among different methods of internal consistency, the coefficient $\alpha$ (Guttman, 1945; Cronbach, 1951) is the most commonly utilized method (Abell, Springer and Kamata, 2009). The coefficient $\alpha$ evaluates the reliability of a set of measures by examining the consistency with which people answer each item in the set. Thus, the Cronbach's coefficient alpha is often calculated to determine the extent of homogeneity of the scale. It varies from 0 to 1, with higher value indicating higher reliability. A commonly accepted standards for its evaluation is 0.60 or greater values (Abell, Springer and Kamata, 2009, p. 93). In their seminal paper, Ryan and Connell (1989, p. 748) provided the statistical justification for assessing reliability on a scale of items differing in degree and in kind -such as in the OPHI's scale- on the basis of the continuum of autonomy of extrinsic motivation. ${ }^{21}$ Therefore, beside assessing the internal consistency of the scale, the structure of association among different items is analyzed. Being ordinal variables associated to response items on a four-point scale, the Kandall tau-b coefficient measures the nature and strength of the association among items. ${ }^{22}$ In particular, SDT predicts controlled motivations, such as external and introjected behavioral regulations, to be negatively associated with response items measuring identified and integrated motivations. The following subsections investigate the reliability of the scale for each domain.

\section{Employment}

The module on employment was administered only to those 23 women declaring to be involved in a secondary occupation. The great majority of them was not subjected to any external pressure to be employed (96\%). Accordingly, they declared not at all true $(91 \%)$ and not very true $(4 \%)$ someone insisted they had to work. Rather, they decide to be employed for gaining respect and approval of people $(96 \%)$ and because they personally believe it is important and valuable (96\%). Also, 78\% of informants considered various options for work and they value what they do. With regards to reliability, Cronbach's alpha is higher for the scale covering the four types of extrinsic motivations $(\alpha=0.71)$ rather than the five-point scale including also the 'no control' modality $(\alpha=0.60)$. Furthermore, Cronbach's alpha for identified and integrated regulation is particularly high $(\alpha=0.80)$ suggesting the feasibility of implementing a shorter module for measuring agency in the domain of employment. In terms of internal association of items, results point out a strong and negative association between external regulation on the one hand and identified and integrated motivation on the other hand. In turn, the same applies to introjected and identified and integrated motivations. Also the positive and relatively strong association between identified and integrated motivations confirms the internal consistency of the scale (Table 2)

\footnotetext{
21 "We then propose that an appropriate model for describing perceived locus of causality for one's own actions conforms to a simplexlike or ordered correlation structure. The simplex concept is derived from Guttman's (1954) radix theory, which describes ordered relations between correlated variables. In a simplex variables are ordered in terms of complexity or conceptual similarity, such that those deemed more similar correlate more highly than those that are hypothetically more discrepant. When arranged in a matrix, a perfect simplex model evidences its largest correlation along a main diagonal, and these increasingly taper off as one moves away from that diagonal. Guttman argued that a simplex model reflects an ordered arrangement along a parameter of variables that also embody qualitative differences".

${ }^{22}$ In this regard, it would be key to revise the scale of the Module on Agency possibly towards the adoption of a Likert scale of five or seven points to allow for an improvement of future quantitative analysis.
} 
Table 2: Kendall's tau b coefficient for autonomy in employment-domain ( $n=23)$

\begin{tabular}{lccccc}
\hline \hline & No control & External & Introjected & Identified & Integrated \\
No control & 1.00 & & & & \\
External & -0.22 & 1.00 & & & \\
Introjected & 0.00 & 0.15 & 1.00 & & \\
Identified & 0.22 & -0.95 & -0.15 & 1.00 & \\
Integrated & 0.27 & -0.61 & -0.26 & 0.64 & 1.00 \\
\hline
\end{tabular}

Table 3: Kendall's tau b coefficient for autonomy in household duties ( $n=134$ )

\begin{tabular}{lccccc}
\hline \hline & No control & External & Introjected & Identified & Integrated \\
No control & 1.00 & & & & \\
External & 0.09 & 1.00 & & & \\
Introjected & -0.02 & $-0.26^{* *}$ & 1.00 & & \\
Identified & 0.03 & $-0.26^{* *}$ & $0.22^{*}$ & 1.00 & \\
Integrated & 0.09 & -0.11 & -0.04 & -0.02 & 1.00 \\
\hline Note: ${ }^{*} p$-value $<0.05 ; * * p$-value $<0.01 ;$ & & & &
\end{tabular}

\section{Household duties}

In investigating reasons behind the choice of engaging in household duties as primary occupation, the sample distribution points out external pressure (i.e. someone else insisted that I do this work, if I do not there would be problems), was completely true merely for $11 \%$ of respondents. The evident absence of direct external demand is confirmed also by responses to questions related to the decision-making process occurring at the household level, which identifies this domain as the only life's sphere on which women detain direct control (Table 1). Yet, 58\% of women declared they did not have a choice for doing household duties because there was no one else to do. Furthermore, the bulk of the sample (94\%) declared to do household duties because people around them would approve them and respect them for doing so. If they did not engage in such behavior, a feeling of guilt and shame would indeed arise (i.e. introjected regulation). Also, the majority of respondents (99\%) consider their tasks as housewives as important and valuable (i.e. identified regulation) and most of them $(97 \%)$ value such arrangements (i.e. integrated regulation). In terms of internal consistency of the scale, the positive and statistically significant association between introjected motivation and identified does not confirm the continuum of autonomy (Table 3). Also, the low values of the Cronbach's alpha coefficient are particularly expected due to the lack of internal consistency of the scale detected in the observed frequency distribution.

\section{Responses to a health crisis}

The domain of health focuses specifically on those possible reasons according to which women respond in certain ways to an health crisis occurring at the household level. Despite the majority of respondents (74\%) perceived themselves as having the ability to project the health of themselves and members of their household, external pressure is a motivation through which women regulate their behavior in responses to an health crisis. Thus, almost $72 \%$ of the sample declared completely true to do whatever the spouse or someone else suggests them to do. Also, responding to an health crisis as others expect one to behave (i.e. introjected regulation) was completely true for a high percentage of respondent $(79 \%)$. The process of internalization of values can be particularly detected in the frequency 
Table 4: Kendall's tau b coefficient for autonomy in responding to an health crisis $(n=134)$

\begin{tabular}{lccccc}
\hline & No control & External & Introjected & Identified & Integrated \\
No control & 1.00 & & & & \\
External & 0.01 & 1.00 & & & \\
Introjected & $-0.26^{* *}$ & 0.10 & 1.00 & & \\
Identified & 0.03 & $-0.38^{* *}$ & -0.07 & 1.00 & \\
Integrated & -0.08 & $0.16^{*}$ & $0.18^{*}$ & -0.07 & 1.00 \\
\hline
\end{tabular}

Note: ${ }^{*} p$-value $<0.05 ; * *$-value $<0.01$

distribution of identified regulation. When asked whether in the circumstance of an health crisis, an informant does whatever she believes is important and right, almost half the sample declared this is not the case. Yet, almost the entire sample declared to consider various alternatives and do what fits with their values and situation- whether it is to treat it at home or in hospital or elsewhere. Also, the analysis of the internal relationship among items points out a positive and statistically significant association between external pressure and integrated motivation. Hence, in responding to an health crisis women consider various options and do what fits with their values and situation, which in turn can be to do whatever the spouse or some else suggest them to do. The same reasoning applies to the association between introjected and integrated regulations, which is positive and statistically significant. Thus, considering various options and doing what fits with one's values and situation appear to be related to acting as others expect and approve (Table 4). Moreover, the highest coefficient of Cronbach's alpha (0.58) results in the scale covering only external pressure and identified motivation.

\section{Mobility}

For the domain of mobility, the survey instrument investigates why women do so when they move around the community or stay inside the house. External pressure converging into the practical need of having to ask permission in order to go out $(99 \%)$ and being careful when moving around the community so people do not speak badly (97\%) (i.e. introjected regulation) is the common denominator for almost the entire sample. Instead, the degree to which women consider themselves as relatively autonomous in moving around the community is what diversifies observations. Thus, a small proportion (32\%) claimed completely true and somewhat true that if it is important to go out they will do so no matter what. Furthermore, an even higher number of informants (41\%) point out if they want to go out (or to stay in for that matter) they are able to think about it and freely decide to do what seems the best, pointing out no restrictions in this respect (i.e. integrated regulation). In terms of internal consistency, the analysis of the association of response items confirms the continuum of autonomy underlying the scale. Indeed, having no options of freely going out is positively and statistically significantly associated with being in need of asking permission to go out and also with being in need to be careful when one goes out so that people do not speak badly. Furthermore, having no options is also negatively and significantly associated with being able to go out if it is important and also with having no restriction in this respect. External pressure is positively and significantly associated with introjected regulation indicating the need of asking permission to go out in relation to punishment from the community if a woman moves around freely without permission. On the other hand, having to ask permission to go out (external pressure) is negatively associated with identified and integrated motivations. Furthermore, the highest alpha's coefficient is found in relation to the two items measuring higher degrees of relative autonomy, namely identified and integrated $(\alpha=0.66)$ whispering the feasibility for a shorter version of the module (Table 6). 
Table 5: Kendall's tau b coefficient for autonomy in mobility ( $n=134)$

\begin{tabular}{|c|c|c|c|c|c|}
\hline No control & $\begin{array}{c}\text { No control } \\
1.00\end{array}$ & External & Introjected & Identified & Integrated \\
\hline External & $0.23^{* *}$ & 1.00 & & & \\
\hline Introjected & $0.19 * *$ & $0.26^{* *}$ & 1.00 & & \\
\hline Identified & $-0.21 * *$ & $-0.19 *$ & -0.05 & 1.00 & \\
\hline Integrated & $-0.21 * *$ & $-0.19 *$ & $-0.15^{*}$ & $0.48^{* *}$ & 1.00 \\
\hline
\end{tabular}

Note: ${ }^{*} p$-value $<0.05 ; * *$-value $<0.01$

Table 6: Internal consistency Reliability for autonomy in mobility-Cronbach's alpha coefficient values ( $n=134)$

\begin{tabular}{lr} 
Cronbach's alpha (MOAG1, MOAG2, MOAG3, MOAG4, MOAG5) & 0.59 \\
Cronbach's alpha (MOAG2, MOAG3, MOAG4, MOAG5) & 0.54 \\
Cronbach's alpha (MOAG1, MOAG4, MOAG5) & 0.60 \\
Cronbach's alpha (MOAG4, MOAG5) & 0.66 \\
\hline
\end{tabular}

\section{Relative autonomy and internalization of values in different domains}

Overall, a crucial distinction among domains arises. In particular, the internal association of items in the domains of household duties and responses to an health crisis indicates a positive relationship between response items pertaining to 'controlled motivation' and to 'relative autonomous' behavioral regulations. On the contrary, the same responses' structure does not apply to the domains of employment and mobility. Accordingly, the higher Cronbach's alpha coefficients are reported for the latter spheres. In interpreting such results, particular care should therefore be devoted to the phenomenon of internalization of values. Thus, in the domain of household duties and responses to an health crisis, the association of relative autonomous items with controlled motivations suggests informants have fully integrated patriarchal social norms into their self. As result, they are relatively autonomous in choosing toward the dismissal of their decision making power because of expectations regarding rewards and punishment (e.g. avoiding feeling ashamed and guilty) (Table 3). Instead, in the domain of employment and mobility -despite the great majority of women needs to ask permission to go out- a clear distinction among informants emerges, as detected in the analysis of association of items. To further investigate such interpretation, an analysis of the validity of indicators among domains is therefore performed.

\section{Constructing validity of agency data}

The validity of a survey instrument, items and scale is the second psychometric property to assess on sample statistics and prior to data analysis. Validity refers to how well a survey instrument measure what intends to measure. Therefore, it is an important indicator of a survey instrument's accuracy (Fink: 2003, p. 30). Constructing validity of a new survey instrument requires detecting and demonstrating that people with certain characteristics measured through the new measure differs significantly from other individuals not having those same characteristics. With regards to the present investigation, differences between empowered and disempowered are therefore investigated. To such aim, a Relative Autonomy Index (RAI) is constructed in the four domains. Before performing correlation analysis between such indicator and other key variables to investigate possible differences between empowered and disempowered, specific space is devoted to the analysis of the distribution of the indicator of relative autonomy in different domains. 


\section{Agency freedom among basic domains}

Does being relatively autonomous in one specific domain necessarily mean being relatively autonomous also in another domain? Following Alkire and Chiappero-Martinetti (2008), an index measuring the degree of relative autonomy is constructed. ${ }^{23}$ In particular, the larger the index is, the greater is the relative autonomy of the corresponding practice (Chirkov, 2003, p. 102). By taking the arbitrary value of zero as cut-off point for identifying those empowered (above zero) and those disempowered (below zero), the distribution of RAI varies greatly according to domains. With regards to household duties, the strong concentration of RAI around the median, which takes on the value 6, points out women are highly autonomous in their choices of being housewives. Accordingly, only few observations in the lower tail of the distribution identify those women who are rather motivated by forces alien to the self in performing their daily household tasks (Figure 1). In the domain of health, the median is attested on a negative value (-3). Observations detected above the cut-off point indicate women who are empowered in terms of their capability of responding to an health crisis in the way they consider important and valuable. Yet, care is to be devoted in interpreting such indicator. The analysis of association among items reveals such relative autonomy to be rather linked to the internalization of an agency's structure skewed towards patriarchal values. Furthermore, the indicator of relative autonomy in the domain of employment applies to the 23 informants declaring to be involved in a secondary occupation (Figure 3). Also, in such domain only very few observations point out to external coercion as main motivation for the choice of being employed. Dramatically different is instead the ability of women to move freely around the community also when they consider important to do so. The median for the domain of mobility is -9 pointing out to a strong concentration of women on a very low level of empowerment. ${ }^{24}$ Only very few informants $(n=20)$ reported a higher degree of relative autonomy in moving around the community (Figure 4).

\section{Validity of agency in the domain of mobility}

Given low variation registered in the household domain, the few observations in the domain of employment, and the low reliability of the scale in the domain of responses to a health crisis, the analysis of validity of the survey instrument focuses in particular on the domain of mobility. To test the validity of RAI in such domain, we hypothesize the indicator correlates negatively with the Body Mass Index (BMI) and positively with the time spent around the community, that are two measures of similar characteristics (i.e. convergent validity). As result, agency in mobility correlates negatively and in a statistically significant way with time spent relaxing and cooking, which are activities performed inside the dwelling unit, whereas it does correlate positively and in a statistically significant way with time

\footnotetext{
${ }_{23}$ Alkire and Chiappero-Martinetti (2008) discuss the arbitrarily chosen weights in the formula to construct RAI and apply Multidimensional Scaling Technique (MST) in order to find validation of the weight system proposed in SDT.

${ }^{24}$ The frequency distribution reveals $85 \%$ of women score a RAI value below zero, whereas only 20 women out of 134 ranked a RAI value equal or above zero (15\%). The mode is -9 with 48 observations ranking such value. For interpreting such indicator correctly, it is important to remind descriptive statistics pointing out the need to ask permission to go out for almost the entire sample. Thus, those women ranking higher value of RAI in the domain of mobility they do need to ask permission like other less empowered women, but they also declared a certain degree of freedom to move around if they consider it important and valuable.
} 
Table7: Correlation Matrix Autonomy and Time Use activities

\begin{tabular}{|c|c|c|c|c|c|c|c|c|c|}
\hline & RAIm & Sleep & Relax & Eat & Weeding & Cooking & Cleaning & Pchildcare & Travel \\
\hline RAIm & 1 & & & & & & & & \\
\hline Sleep & 0.07 & 1 & & & & & & & \\
\hline Relax & $-0.14^{*}$ & -0.09 & 1 & & & & & & \\
\hline Eat & -0.13 & $0.19 * *$ & -0.12 & 1 & & & & & \\
\hline Weeding & -0.26 & -0.28 & 0.20 & -0.28 & 1 & & & & \\
\hline Cooking & $-0.14^{*}$ & $-0.22 * *$ & -0.08 & $-0.23^{* *}$ & $-0.48^{*}$ & 1 & & & \\
\hline Cleaning & $0.15^{*}$ & 0.09 & $-0.25^{* *}$ & 0.09 & $-0.67 * *$ & 0.02 & 1 & & \\
\hline Pchildcare & $0.20 *$ & -0.08 & -0.03 & -0.14 & 0.13 & -0.03 & 0.16 & 1 & \\
\hline Travel & 0.17 & -0.04 & -0.05 & -0.29 & -0.09 & -0.15 & -0.34 & 0.15 & 1 \\
\hline
\end{tabular}

dedicated to cleaning the dwelling units, which requires a degree of movement also outside the physical area of the house as well as with physical care of children which requires washing and taking care of their physical conditions. Also, the indicator does correlate positively with the amount of time spent in travelling. However, the association between such two variables is not statistically significant (Table 7). Instead, strong evidence of the validity of the indicator is to be found with regards to anthropometry, such as with the BMI, computed for 90 observations. Indeed, the correlation between RAI in mobility and the BMI of informants is negative and statistically significant. Furthermore, to shed light on the relationship between RAI and household's resources, Drèze and Sen's (1999) writings on agency in India predict autonomy to be negatively correlated with wealth, the rationale being poverty as lack of monetary resources leads women to engage in remunerative work and to be less accustomed to gendered stereotypes related to social status. Therefore, the framework would on average predict that poverty as lack of relative autonomy characterizes most those women who belong to the higher quintile of the wealth's distribution, whereas those at the bottom would be characterized by a higher degree of relative autonomy.

To empirical test such hypotheses, we follow Filmer and Pritchett (2001) who have proposed in the absence of information on income and consumption- to proxy measure for wealth by constructing a linear index from asset ownership and household characteristics. We, therefore, perform a Principal Component Analysis (PCA) on five variables related to income, that are number of bigha of land the household owns, number of livestock converted in Tropical Livestock Unit (TLU) the household owns, number of rooms in the house, adjusted monthly agricultural value and number of assets in the household. ${ }^{25}$ In including the number of livestock, the indicator is particularly sensitive to those livelihood strategies the household may implement to increase its food security in times of crisis. Furthermore, we extracted one component, labeled wealth, that explains $62 \%$ of total variability. ${ }^{26}$ When looking at the association of RAI in the domain of health, the relationship between relative autonomy in responding to an health crises and wealth is positive (0.19) and statistically significant at 0.05 . If interpreted in terms of internalization of values, such results would confirm the hypothesized interpretation. That is, a high internalization of patriarchal values is strictly linked to social status of women in the wealth distribution. The higher the wealth of the household, the higher the internalization of values, the higher the relative autonomy in transferring the decision making power in the hands of household's members.

\footnotetext{
${ }_{25}$ Bigha is the unit of measurement for area of land commonly in use in South Asia, particularly in Nepal, Bangladesh and some States in India. However, it is not a part of an unit's nomenclature and varies across countries. According to enumerators, in the state of Uttar Pradesh 1 acre corresponds to 0.652 bigha. With regards to sample statistics, the mean value is 12 bigha $(\mathrm{sd}=20.90)$. With reference to its distribution, $51 \%$ households did not own any land. Instead, among landowners, 68\% owned at least 25 bigha of land, whereas the remaining households owned a bigger plot.

${ }^{26}$ The loadings of the first principal component associated to the standardized resources-related variables are as follows: 0.482 (lando), 0.445 (housingasst), 0.451 (hroom), 0.427 (avalue3) 0.427 (lstok).
} 
On the contrary, for the indicator of relative autonomy in mobility, which we assume to be reflecting a purer form of authenticity on the basis of the internal consistency of the scale, correlation analysis between the wealth index and RAI in mobility points out a weak association (-0.09) and not statistically significant. Yet, the sign recorded is negative. Also, correlation coefficients for RAI in mobility on one hand and indicators entering the PCA on the other hand indicate a negative association between relative autonomy and wealth. Moreover, a phenomenon of social exclusion - detected by multiple and simultaneous negative signs in the correlation structure of RAI in mobility with other socio-economic indicators- of those more empowered in mobility arises. In particular, when looking at the correlation structure of RAI with other socio-economic variables, such as years of education (edu), dependency ratio (ratio between the number of children below age 15 over the total number of household members), the age at marriage of the informant, associations are weak and not statistically significant but the sign is negative for all variables. The only exception confirming the rule is to be found in the relation between autonomy in mobility and the number of children below 15 years (dratio) (Table 8). Turning to descriptive results, indeed, only 21 women results being empowered in the realm of mobility. Among them, 14 are landless and 8 are non-literate. Also, the association between RAI and control over decisions regarding how to spend money within the household is positive (0.04) suggesting an increase in relative autonomy is associated with lack of control over such decision on the side of the informants.

Table 8: Correlation Matrix for RAI in the domain of Mobility and background characteristics

\begin{tabular}{|c|c|c|c|c|c|c|c|c|}
\hline & RAI & Wealth & $\begin{array}{r}\text { Years of } \\
\text { schooling }\end{array}$ & $\begin{array}{c}\text { Age } \\
\text { marriage }\end{array}$ & Dratio & Breastfeed & MBMI & FBMI \\
\hline RAI & 1 & & & & & & & \\
\hline Wealth & -0.09 & 1 & & & & & & \\
\hline Years of schooling & -0.03 & 0.56 & 1 & & & & & \\
\hline Age marriage & -0.02 & 0.42 & 0.64 & 1 & & & & \\
\hline Dratio & 0.07 & -0.36 & -0.45 & -0.49 & 1 & & & \\
\hline MBMI & -0.15 & 0.04 & 0.14 & 0.33 & -0.00 & 0.10 & 1 & \\
\hline FBMI & -0.09 & 0.10 & 0.17 & 0.25 & -0.02 & 0.20 & 0.93 & 1 \\
\hline
\end{tabular}


Figure 1: Distribution of $\mathrm{R} A I$ in the domain of household duties $(\mathrm{n}=133)$

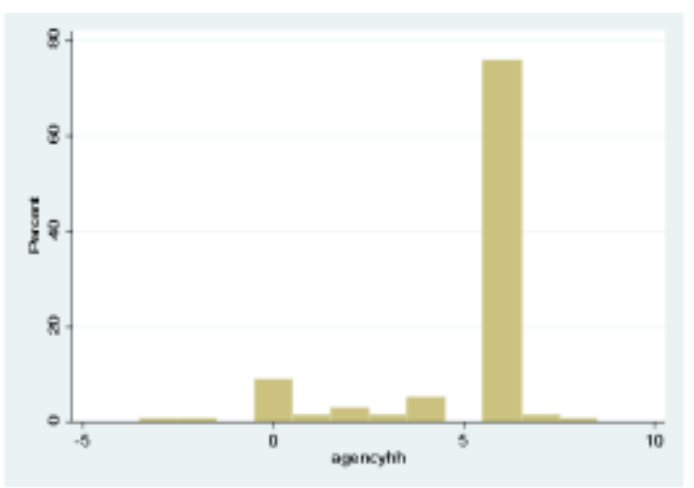

Figure 3: Distribution of $\mathrm{RAI}$ in the domain of employment $(\mathrm{n}=23)$

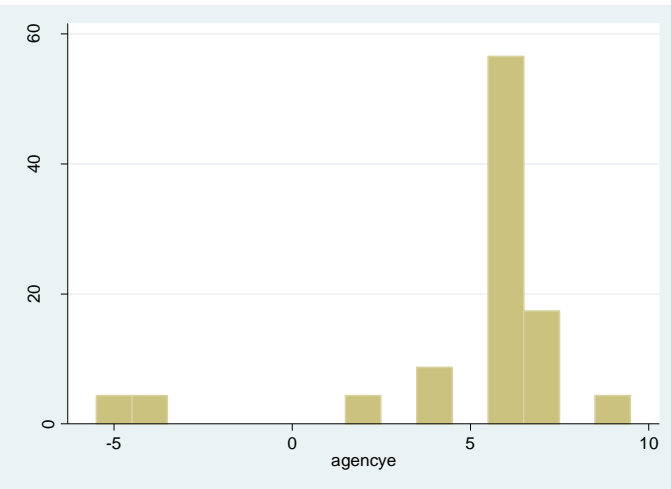

Figure 2: Distribution of $\mathrm{R} A I$ in the domain of response to an health crisis $(\mathrm{n}=134)$

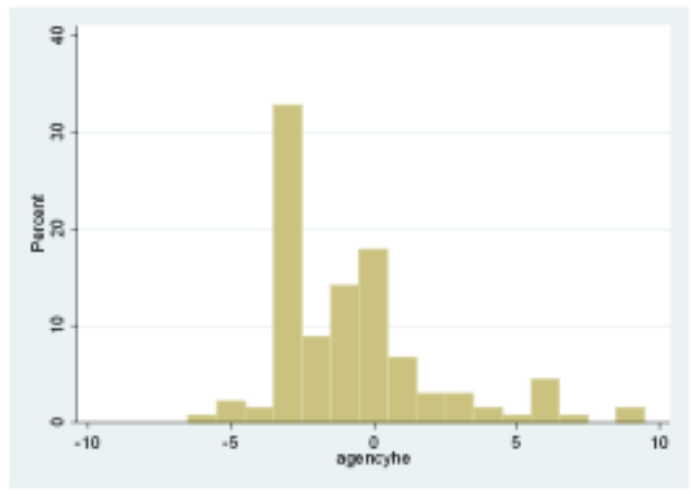

Figure 4: Distribution of RAI in the domain of mobility $(\mathrm{n}=134)$

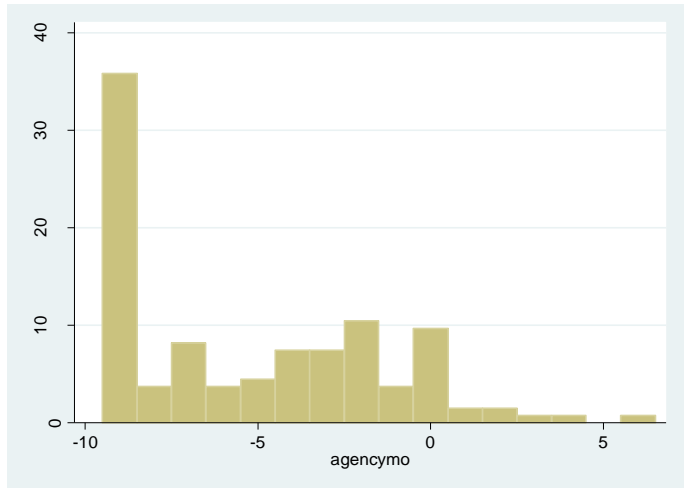




\section{Conclusion}

Empowerment increasingly plays a crucial role in poverty reduction strategies due to its positive effects in breaking down vicious circles of deprivation. Nevertheless, universal consensus on its analytical framework and appropriate measurement has not been reached yet. In particular, the concept has been mainly translated into monetary indicators neglecting individual heterogeneity in converting resources into different levels of empowerment and overlapping with the account of poverty as lack of income. This paper empirically investigates the properties of an indicator measuring directly the degree of relative autonomy of female informants living in a rural patriarchal village in Uttar Pradesh, India. In particular, the main objective was to shed light on previously neglected dimensions of empowerment, such as effect power, autonomy and other regarding goals and test whether achievements in different domains overlap.

The analysis yields domain-dependent results. In particular, the analysis of the internal structure of the scale indicates a process of internalization of values in the domain of household duties and responses to an health crisis detected through the positive association of relative autonomous behavioral regulations with controlled motivations. On the other hand, the domain of mobility and employment does not suffer from such bias being closer to the autonomy's continuum hypothesized. Also, achievements among domains do not overlap. Thus, being autonomous in one domain does not imply being autonomous in another domain. Furthermore, being relatively autonomous in moving around the community is associated negatively with wealth at the household level suggesting poverty as lack of relative autonomy and as lack of resources are to be treated as two separate exercises both at the conceptual and measurement level. Moreover, multiple and simultaneous negative signs in the correlation structure between such indicator and other socio-economic variables suggest a phenomenon of social exclusion of the small segment identified as empowered.

In terms of policy prescription at the village level, therefore, a viable strategy to advance empowerment would look at collective capabilities rather than targeting individuals. As Sen (2002, p. 11) states "in assessing the significance of the process aspect, we have to go beyond the importance that a person may attach to processes that are critical to her own freedom, and take into account the procedural relevance of such social concerns as rights and justice". In this regard, future research could investigate the possibility of complementing the previous focus on the relation between the individual and his/her own means for agency with a view on the relational goods for empowerment assessing the social capital allowing empowered choice to take place. Also, future research could take more into account intrinsic motivation, which refers to "the inherent tendency to seek out novelty and challenges, to extend and exercise one's capacity, to explore and to learn" and "doing of an activity for the inherent satisfaction of the activity itself", which in turn results in fostering self-motivation and personalityintegration, that is the purest form of autonomy. In this regard, supplementary and counter-factual questions could prove to be an extraordinary informational basis for direct-domain specific indicators of freedom. 


\section{References}

Abell, N., Springer, D.W., Kamata, A. (2009) Developing and Validating Rapid Assessment Instruments, Oxford University Press

Alkire, S. (2005) Subjective quantitative studies of buman agency, Social Indicators Research, 74, pp. 217-260

Alkire S. (2007) The Missing Dimensions of Poverty Data: An introduction, OPHI Working Paper Series

Alkire, S. (2008) Concepts and Measures of Agency, OPHI Working Paper Series, No. 9

Alkire, S., Chiappero-Martinetti E. (2008) Towards a multidimensional measure of buman agency, OPHI Working Paper No. 12

Alkire, S., Foster, J. (2011) Counting and multidimensional poverty measurement, Journal of Public Economics, Vol. 95, pp. 476-487

Chirkov, V., Ryan, R. M., Kim, Y., Kaplan, U. (2003) Differentiating autonomy from individualism and independence: A self-determination theory perspective on internalization of cultural orientations and well-being, Journal of Personality and Social Psychology, Vol. 84, pp. 97-110

Comin, F., Qizilbash, M., Alkire, S. (2008) The Capability Approach. Concepts, Measures and Applications, Cambridge University Press

Drèze, J., Sen, A. (1999) The Amartya Sen \& Jean Drèze Omnibus, Oxford University Press

Ibrahim, S., Alkire, S. (2007) Agency and Empowerment: A proposal for Internationally Comparable Indicators, Oxford Development Studies, Vol. 35, No. 4, pp. 379-403

Fink A.G. (2003) The Survey Kit, Second Edition, Sage Publication

Narayan, D. (2002) Empowerment and Poverty Reduction. A sourcebook, The International Bank for Reconstruction and Development, The World Bank

Narayan, D. (2005) Measuring empowerment. Cross-disciplinary perspectives, The International Bank for Reconstruction and Development, The World Bank

Nussbaum, M. (2000) Women and Human Development: The Capabilities Approach, Cambridge University Press, Cambridge

Ryan, R. M., Connell, P. (1989) Perceived locus of causality and internalization. Examining reasons for acting in two domains, Journal of Personality and Social Psychology, No. 5., pp. 749-761

Ryan, R. M., Deci, E. L. (2000) Self-determination theory and the facilitation of intrinsic motivation, social development and well-being, American Psychologist, 55, pp.68-78

Pritchett, L. H., Filmer, D. (2001) Estimating wealth effect without expenditure data-or tears. An application to enrollments in States of India, Demography, Vol. 38, No.1, pp.115-132

Sammam, E., Santos, M. E. (2009) Agency and Empowerment: A review of concepts, indicators and empirical evidence, Paper prepared for the 2009 Human Development Report in Latin America and the Caribbean 
Sen, A. (1977) Rational Fools: A critique of the Behavioral Foundation of Economic Theory, Philosophy and Public Affairs, Vol.6, No. 4, pp. 317-344

Sen, A. (1982) Choice, Welfare and Measurement, Harvard University Press

Sen, A. (1985) Well-being, Agency and Freedom: The Dewey Lectures 1984, Journal of Philosophy, Vol. 82, No.4, pp. 169-221

Sen, A. (1990) Gender and Cooperative Conflicts, in Thinker, I., "Persistent Inequalities: Women and World Development", Oxford University Press, pp. 123-149

Sen, A. (1994) The formulation of rational choice, The American Economic Review, Vol. 84., No. 2, pp. 385-390

Sen, A. (1999) Reason before Identity: The Romanes Lecture, Oxford University Press

Sen, A. (2002) Rationality and Freedom, Harvard University Press

Sen, A. (2009) The Idea of Justice, Penguin Books

Silva-Leander, S. (2011) Revealed Meta-Preferences: Axiomatic Foundations of Normative Assessments in the Capability Approach, OPHI Working Paper No. 48

Silva-Leander, S. (2011) On the Possibility of Measuring Freedom: A Kantian Perspective, OPHI Working Paper No. 49 


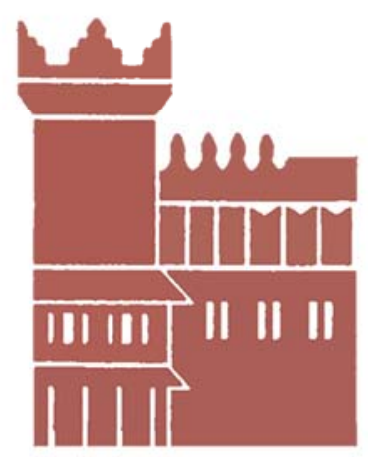

Alma Mater Studiorum - Università di Bologna DEPARTMENT OF ECONOMICS

Strada Maggiore 45

40125 Bologna - Italy

Tel. +39051 2092604

Fax +390512092664

http://www.dse.unibo.it 